\title{
К ВОПРОСУ ОБ УНИФИКАЦИИ ЗАКОНОДАТЕЛЬСТВА О ПРАВООХРАНИТЕЛЬНОЙ СЛУЖБЕ
}

И нститут правоохранительной службы занимает особое место в служебном праве России как подотрасли административного права. Это обусловлено как специфическими целями правоохранительной деятельности - обеспечением безопасности, законности и правопорядка, борьбой с преступностью, защитой прав и свобод человека и гражданина, так и исключительной активностью реформирования института правоохранительной службы, которое осуществляется при отсутствии базового закона о правоохранительной службе и легально закрепленных концептуальных начал такого реформирования.

Сложность реформирования института правоохранительной службы обусловлена и реализацией административной реформы, цель которой - формирование «сервисного» публичного управления, нацеленного на минимизацию административных барьеров и повышение качества и доступности государственных услуг. В этой связи реформирование института правоохранительной службы сопровождается выделением из сферы деятельности отдельных правоохранительных органов (Федеральная таможенная служба, Федеральная миграционная служба, Министерство внутренних дел, Государственная противопожарная служба МЧС РФ) таких ее видов, которые являются услугами, и трансформацией отношений по поводу предоставления этих услуг в сферу государственной гражданской службы.

Законодательство о правоохранительной службе исключительно объемно, оно детально регулирует порядок ее прохождения в различных правоохра- нительных органах. При этом институт правоохранительной службы следует признать достаточно «громоздким» правовым явлением. Вопросы осуществления правоохранительной деятельности и функционирования правоохранительной службы, ее обеспечения, связи с другими сферами государственного управления регулируются прямо или косвенно нормами более чем 110 федеральных законов, 62 указов Президента РФ, 140 постановлений Правительства РФ, помимо нормативно-правовых актов отраслевых федеральных органов исполнительной власти и иных государственных органов, в которых осуществляется правоохранительная служба. При этом следует признать непоследовательность и некую спешку регулирования деятельности сотрудников правоохранительной службы - например, нормы Федерального закона от 7 февраля 2011 г. «О полиции» ${ }^{1}$, несмотря на непродолжительный срок его действия, уже менялись законодателем 9 раз.

В теории служебного права диссертационные исследования вопросов организации и функционирования института правоохранительной службы условно можно разделить на два направления. В рамках каждого из них ни один из авторов не обошел рассмотрения вопроса об унификации законодательства о правоохранительной службе в контексте заявленной темы как одной из ключевых задач повышения эффективности реализации правоохранительных функций.

Первое направление связано с изучением особенностей правоохранительной службы в отдельных пра-

См.: СЗ РФ. - 2011. - № 7. - Ст. 900. 
воохранительных органах, второе - с комплексным исследованием проблем, касающихся правоохранительной службы в целом. Наиболее активно в первом направлении изучались особенности правоохранительной службы в органах внутренних дел ${ }^{2}$, в том числе ее социально-культурные аспекты ${ }^{3}$.

Ко второму направлению можно отнести более 10 работ, которые осуществлялись после формирования новой системы государственной службы, закрепленной в Федеральном законе от 27 мая 2003 г. «О системе государственной службы Российской Федерации» ${ }^{4}$.

В рамках данных работ выделим особо две темы, посвященные институту правоохранительной службы в целом. Первая тема - «Государственная правоохранительная служба: системные свойства, функции, правовое обеспечение» ${ }^{5}$ В условиях формирования правоохранительной службы, полагает разработчик данной темы А.М. Артемьев, выполнение возложенных на ее сотрудников и служащих задач невозможно без четкой правовой и единой законодательной базы самой правоохранительной службы во всех федеральных органах власти, что требует скорейшего принятия единого основополагающего нормативного акта - закона «О правоохранительной службе Российской Федерации».

Вторая тема, которую исследовал К.А. Погребежский, — «Правовое обеспечение государственной правоохранительной службы и пути его

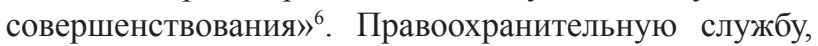

\footnotetext{
2 См.: Дикажев М.М. Организационные и правовые вопросы прекращения службы в органах внутренних дел и социальной защиты пенсионеров: Автореф дис. ... канд. юрид. наук. - М.,1999; Цымбалов Д. Н. Обеспечение прав и законных интересов сотрудников органов внутренних дел: Конституционно-правовые аспекты: Автореф дис. ... канд. юрид. наук. - СПб., 2005; Концелидзе Р.У. Правовая и социальная защита сотрудников милиции: Автореф. дисс. ... канд. юрид. наук. - М.,1993, и др.

3 См.: Арсентьева А.Г. Нравственно-правовая культура и ее формирование у сотрудников органов внутренних дел: Автореф дис. ... канд. юрид. наук. - СПб., 1996: Пролетенкова C.Е. Особенности реализации конституционных прав свободы совести и свободы вероисповедания военнослужащими, сотрудниками ОВД и иных правоохранительных органов: Автореф. дис. ... канд. юрид. наук. - СПб., 2005. и др.

4 СЗ РФ. - 2003 - № 22. - Ст. 2063.

5 См.: Артемьев А.М. Государственная правоохранительная служба: системные свойства, функции, правовое обеспечение: Автореф. дис. ... д-ра юрид. наук. - М., 2008.

6 См.: Погребежский К.А. Правовое обеспечение государственной правоохранительной службы и пути его совершенствования: Автореф. дис. ... канд. юрид. наук. - М., 2010.
}

по мнению ученого, необходимо рассматривать как единый организационный и административно-правовой институт, что предопределяется, прежде всего, единым предметом служебно-правовых отношений, который составляют такие направления служебной деятельности (функции), как обеспечение безопасности, законности и правопорядка, борьба с преступностью и защита прав и свобод человека и гражданина. Единство административно-правового института правоохранительной службы как совокупности однородных общественных отношений требует, в свою очередь, комплексного правового регулирования этой служебной профессиональной деятельности.

Следует отметить одну из работ, имеющую культурологический аспект исследования деятельности сотрудников правоохранительных органов - «Профессиональная правовая культура в сфере правоохранительной службы» ${ }^{7}$ По мнению ее автора О.Ф. Павлова, культурологический подход позволяет рассматривать правоохранительную службу в качестве единого объекта культурных воздействий и одновременно источника формирования ценностей, определяющих социальную практику защиты прав и свобод человека и гражданина в сфере обеспечения безопасности, законности и правопорядка, борьбы с преступностью.

Поощрение является одним из действенных методов повышения дисциплины правоохранительной службы. В процессе исследования поощрения в свое диссертации А.Н. Караваев ${ }^{8}$, в частности, определяет моменты, которые характерны для дисциплины применительно к государственной службе. Предлагается поощрение и наказание применительно к дисциплине рассматривать через философские категории: содержание и форму, где содержанием будет поощрение и наказание, а формой - дисциплина. В другой диссертационной работе 9 , посвященной служебной дисциплине в правоохранительных органах, К.А. Павленко отмечает наличие полярных подходов к регулированию служебной дисциплины в различных правоохранительных органах. В настоящее время нормативная база служебной дисциплины на правоохранительной службе, по мнению ученого, представляет собой на-

См.: Павлов О.Ф. Профессиональная правовая культура в сфере правоохранительной службы: На примере сотрудника милиции: Автореф. дис. ... канд. юрид. наук. - Н.Новгород, 2005.

См.: Караваев А.Н. Поощрение в системе правоохранительной службы: Автореф. дис. ... канд. юрид. наук. - Саратов, 2005.

9 См.: Павленко К.А. Служебная дисциплина в системе правоохранительной службы Российской Федерации: Автореф. дис. ... канд. юрид. наук. - Воронеж, 2011. 
бор законов и подзаконных актов различной конкретики, по-разному структурированных и устанавливающих возможность применения различных дисциплинарных санкций и мер поощрения. На практике это влечет частую безнаказанность субъектов дисциплинарных правонарушений, высокую латентность исполнения противоправных приказов начальства (руководства).

В.М. Бакун исследуя административно-правовой статус служащих правоохранительной службы ${ }^{10}$, делает вывод о том, что в целом решение проблем правового регулирования статуса государственных служащих правоохранительной службы возможно осуществлять по двум основным направлениям: путем принятия закона «О правоохранительной службе Российской Федерации», который установит единую для всех служащих правоохранительной службы систему прав, обязанностей, ограничений, запретов, гарантий деятельности, ответственности, и путем внесения изменений и дополнений в федеральные законы, определяющие статус отдельных видов правоохранительных органов, которые в соответствии со спецификой целей, задач и функций, возлагаемых на правоохранительный орган, определят особенности правового положения служащих и порядок прохождения службы именно в данном органе.

Таким образом, несмотря на различную тематику диссертационных исследований, посвященных правоохранительной службе, их авторы едины в признании крайней необходимости унификации норм законодательства о правоохранительной службе, регулирующих отдельные этапы ее прохождения. И эта унификация должна осуществляться на основе единого федерального закона о правоохранительной службе.

В исследовании проблем унификации законодательства о правоохранительной службе особое значение имеет вопрос о назначении, содержании и принципах правоохранительной службы в системе государственной службы РФ.

В российском праве базовое определение понятия «правоохранительная служба» содержится в Федеральном законе от 27 мая 2003 г. «О системе государственной службы Российской Федерации» ${ }^{11}$.

Согласно ст. 7 данного Закона, правоохранительная служба — вид федеральной государственной службы, представляющей собой профессиональную служебную деятельность граждан на должностях пра-

10 См.: Бакун В.М. Административно-правовой статус служащих правоохранительной службы: Автореф. дис. ... канд. юрид. наук. - М., 2006.

11 См.: СЗ РФ. - 2003. - № 22. - Ст. 2063. воохранительной службы в государственных органах, службах и учреждениях, осуществляющих функции по обеспечению безопасности, законности и правопорядка, по борьбе с преступностью, по защите прав и свобод человека и гражданина. Таким гражданам присваиваются специальные звания и классные чины. Определение содержит следующие ключевые признаки правоохранительной службы:

- цель службы - обеспечение безопасности, законности и правопорядка, борьба с преступностью, защита прав и свобод человека и гражданина,

- принадлежность службы - вид федеральной государственной службы,

- характер службы - профессиональная служебная деятельность,

- статус служащих - граждане, имеющие должности правоохранительной службы, которым присваиваются специальные звания и классные чины,

- организачии, в которых осуществляется служ$\sigma a-$ - государственные органы, службы и учреждения, осуществляющие функции для достижения указанных выше целей службы.

Определение правоохранительной службы как вида федеральной государственной службы, согласно ст. 19 данного Закона применяется со дня вступления в силу федерального закона о правоохранительной службе. Однако в формировании законодательной базы о правоохранительной службе оно играет ключевую роль и служит правовым ориентиром регулирования соответствующих служебных отношений.

Таким образом, в российском служебном праве сложилась уникальная ситуация - не имеющая юридической силы дефиниция выстраивает институт правоохранительной службы при отсутствии единого базового перечня органов, в которых она осуществляется. При этом в отдельных нормативных актах о правоохранительной службе такие перечни в их различных вариациях закреплены. Вместе с тем, исходя из содержания правоохранительной функции - обеспечение безопасности, законности и правопорядка, борьба с преступностью, защита прав и свобод человека и гражданина, а также исходя из статуса сотрудников данных органов, имеющих специальные звания, в такой перечень можно включить следующие властные структуры: Министерство внутренних дел РФ (МВД России); Государственную фельдъегерскую службу РФ (ГФС России); Федеральную таможенную службу РФ (ФТС России); Федеральную службу РФ по контролю за оборотом наркотиков (ФСКН России); Государственную противопожарную службу МЧС России; Федеральную службу исполнения наказаний РФ 
(ФСИН России), находящуюся в ведении Министерства юстиции РФ. Федеральную миграционную службу $(\text { ФМС России })^{12}$.

Из всех перечисленных выше государственных органов только Федеральная миграционная служба и Федеральная таможенная служба подчинены Правительству РФ, остальные находятся в подчинении Президенту РФ напрямую или через соответствующее министерство. Кроме того, правоохранительная служба осуществляется в государственных органах, не являющихся органами исполнительной власти - это Прокуратура РФ и Следственный комитет РФ.

Функционирование такого значимого института служебного права, как институт правоохранительной службы, основано на принщипах построения и функционирования системы государственной службы, закрепленных в ст. 3 данного Закона: это федерализм, законность; приоритет прав и свобод человека и гражданина, их непосредственное действие, обязательность их признания, соблюдения и защиты; равный доступ граждан к государственной службе; единство правовых и организационных основ государственной службы; взаимосвязь государственной службы и муниципальной службы; открытость государственной службы и ее доступность общественному контролю, объективное информирование общества о деятельности государственных служащих; профессионализм и компетентность государственных служащих; защита государственных служащих от неправомерного вмешательства в их профессиональную служебную деятельность как государственных органов и должностных лиц, так и физических и юридических лиц. При этом ч. 2 данной статьи допускает возможность применения других принципов при условии, что они будут установлены федеральным законом о соответствующем виде службы с учетом особенностей вида службы.

Такая возможность законодателем реализована, однако при этом можно отметить отсутствие единого подхода и в отношении содержания, и в отношении способа изложения принципов осуществления служебной деятельности для сотрудников различных правоохранительных органов.

\footnotetext{
12 Одним из самых последних документов, содержащих указанный выше перечень правоохранительных органов, относящихся к ветви исполнительной власти, является Указ Президента РФ от 29 июня 2011 г. «О Комиссии при Президенте Российской Федерации по вопросам кадровой политики в правоохранительных органах» (вместе с «Положением о комиссии при Президенте Российской Федерации по вопросам кадровой политики в правоохранительных органах» // СЗ РФ. - 2011. - № 31. - Ст. 4713.
}

Например, в Федеральном законе от 7 февраля 2011 г. «О полиции» ${ }^{13}$ семь принципов деятельности полиции закреплены в отдельной главе, каждому принципу посвящена отдельная статья. Принципы сформулированы достаточно конкретно - соблюдение и уважение прав и свобод человека и гражданина, законность, беспристрастность, открытость и публичность, общественное доверие и поддержка граждан, взаимодействие и сотрудничество, использование достижений науки и техники, современных технологий и информационных систем.

В Федеральном законе от 30 ноября 2011 г. «О службе в органах внутренних дел Российской Федерации и внесении изменений в отдельные законодательные акты Российской Федерации» ${ }^{14}$ используется иная юридическая техника - законодатель отсылает к основополагающим принципам Федерального закона «О системе государственной службы Российской Федерации», формулирует три иных принципа и затем определяет, что данные принципы реализуются при соблюдении определенных положений. Такой способ изложения принципов усложняет их восприятие и никоим образом не обеспечивает однозначность их понимания.

Для сотрудников Следственного комитета сформулированы не сами принципы, а некие правовые явления, на которых они основаны - единство федеральной централизованной системы следственных органов и учреждений Следственного комитета, подчинение нижестоящих руководителей вышестоящим и Председателю Следственного комитета, осуществление полномочий независимо от федеральных органов государственной власти, органов государственной власти субъектов РФ, органов местного самоуправления, общественных объединений и организаций, иных органов и в соответствии с законодательством РФ; деятельность гласно в той мере, в какой это не нарушает права и свободы человека и гражданина, не противоречит требованиям законодательства РФ об уголовном судопроизводстве, законодательства РФ о государственной и иной охраняемой законом тайне; информирование органов власти, а также населения о результатах следственной деятельности. Для сотрудников прокуратуры три последних позиции сформулированы именно как принципы.

Отметим также, что для правоохранительной службы в Федеральной службе РФ по контролю за оборотом наркотиков, в Федеральной таможенной службе специальные принципы служебной деятельности вообще не сформулированы.

\footnotetext{
13 См.: СЗ РФ. - 2011. - № 7. - Ст. 900.

14 См.: СЗ РФ. - 2011. - № 49 (ч. 1). - Ст. 7020.
} 
Анализ норм, определяющих назначение, содержание и принципы правоохранительной службы в системе государственной службы РФ, позволяет отметить следующие дефекты в данном регулировании:

- отсутствует законодательно установленный перечень государственных органов, в которых осуществляется правоохранительная служба; такой перечень можно установить косвенно, из толкования ряда нормативных актов, определяющих функции данных органов и особенности прохождения в них службы;

- закрепление функций федеральных служб в п. 4 (а) Указа Президента РФ от 9 марта 2004 г. «О системе и структуре федеральных органов исполнительной власти» ${ }^{15}$ (контроль и надзор в установленной сфере деятельности, а также специальные функции в области обороны, государственной безопасности, защиты и охраны государственной границы РФ, борьбы с преступностью, общественной безопасности) не снижает неопределенности в установлении перечня федеральных органов исполнительной власти, в которых осуществляется правоохранительная служба;

- наиболее надежным ориентиром определения такого перечня остается совокупность признаков правоохранительной службы, содержащаяся в ее определении в Федеральном законе «О системе государственной службы Российской Федерации», однако оно не имеет юридической силы;

- основополагающим началам - принципам осуществления правоохранительной службы - законодатель не уделил должного внимания, сформулировав их в разных законах в отсутствие единого подхода и с использованием различных приемов юридической техники, что существенно снижает эффективность правового регулирования отношений в сфере правоохранительной службы; для ряда правоохранительных органов такие принципы вообще не определены, поэтому они должны руководствоваться в своей деятельности только общими принципами государственной службы, закрепленными в Федеральном законе «О системе государственной службы Российской Федерации».

Унификация принципов служебной деятельности для правоохранительных органов имеет особое значение, поскольку это основополагающие начала, формирующие единые подходы к нормативному регулированию деятельности различных видов правоохранительных органов, определение их сущности и назначения; к правоприменительной деятельности, которая должна обеспечивать реальную защиту прав и свобод всех субъектов права, нуждающихся в ней; к внутриорганизационной деятельности, организующей должное осуществление правоохранительной службы ее сотрудниками.

\section{Библиографический список:}

1. Административное право: учебник / под ред. Л.Л. Попова, М.С. Студеникиной. — М.: Норма, 2008. — 992 с.

2. Арсентьева А.Г. Нравственно-правовая культура и ее формирование у сотрудников органов внутренних дел: автореф. дисс. на соиск. уч. ст. ... канд. юрид. наук. - СПб., 1996. - 19 с.

3. Артемьев А.М. Государственная правоохранительная служба: системные свойства, функции, правовое обеспечение: автореф. дисс. на соиск. уч. ст. ... д-ра юрид. наук. — М., 2008., — 23 с.

4. Бакун В.М. Административно-правовой статус служащих правоохранительной службы: автореф. дисс. на соиск. уч. ст. ... канд. юрид. наук. — М., 2006. — 25 с.

5. Бельский К.С. Полицейское право. Лекционный курс / под ред. канд. юрид. наук А.В. Куракина. - М.: Изд-во «Дело и сервис», 2004. - 816 с.

6. Дикажев М.М. Организационные и правовые вопросы прекращения службы в органах внутренних дел и социальной защиты пенсионеров: автореф. дисс. на соиск. уч. ст. ... канд. юрид. наук. - М.,1999. — 22 с.

7. Караваев А.Н. Поощрение в системе правоохранительной службы: автореф. дисс. на соиск. уч. ст. ... канд. юрид. наук. - Саратов, 2005. - 24 с.

8. Концелидзе Р.У. Правовая и социальная защита сотрудников милиции: автореф. дисс. на соиск. уч. ст. ... канд. юрид. наук. - М.,1993. - 20 с.

9. Овсянко Д.М. Государственная служба Российской Федерации: Учеб. пособ. - М.: Юристь, 2008. — 447 с.

10. Павлов О.Ф. Профессиональная правовая культура в сфере правоохранительной службы: На примере сотрудника милиции: автореф. дисс. на соиск. уч. ст. ... канд. юрид. наук. - Новгород, 2005. — 22 с.

15 См.: СЗ РФ. - 2004. - № 25. - Ст. 945. 
11. Павленко К.А. Служебная дисциплина в системе правоохранительной службы Российской Федерации: автореф. дисс. на соиск. уч. ст. ... канд. юрид. наук. - Воронеж, 2011. - 24 с.

12. Погребежский К.А. Правовое обеспечение государственной правоохранительной службы и пути его совершенствования: автореф. дисс. на соиск. уч. ст. ... канд. юрид. наук. - М., 2010. — 26 с.

13. Пролетенкова С. Е. Особенности реализации конституционных прав свободы совести и свободы вероисповедания военнослужащими, сотрудниками ОВД и иных правоохранительных органов: автореф. дисс. на соиск. уч. ст. ... канд. юрид. наук. — СПб., 2005.

14. Цымбалов Д.Н. Обеспечение прав и законных интересов сотрудников органов внутренних дел: Конституционно-правовые аспекты: автореф. дисс. на соиск. уч. ст. ... канд. юрид. наук. СПб., 2005.

\section{References (transliteration):}

1. Administrativnoe pravo: uchebnik / pod red. L.L. Popova, M.S. Studenikinoy. — M.: Norma, 2008. — $992 \mathrm{~s}$.

2. Arsent'eva, A.G. Nravstvenno-pravovaya kul'tura i ee formirovanie u sotrudnikov organov vnutrennikh del: Avtoreferat dissertatsii na soiskanie uchenoy stepeni kandidata yuridicheskikh nauk. — SPb., 1996. - $19 \mathrm{~s}$.

3. Artem'ev A.M. Gosudarstvennaya pravookhranitel'naya sluzhba: sistemnye svoystva, funktsii, pravovoe obespechenie: Avtoreferat dissertatsii na soiskanie uchenoy stepeni doktora yuridicheskikh nauk. - M., 2008. - $23 \mathrm{~s}$.

4. Bakun V. M. Administrativno-pravovoy status sluzhashchikh pravookhranitel'noy sluzhby: Avtoreferat dissertatsii na soiskanie uchenoy stepeni kandidata yuridicheskikh nauk. - M., 2006. - $25 \mathrm{~s}$.

5. Bel'skiy K.S. Politseyskoe pravo. Lektsionnyy kurs / Pod red. kand. yurid. nauk A.V. Kurakina. — M.: Izdatel'stvo «Delo i servis», 2004 g. - $816 \mathrm{~s}$.

6. Dikazhev M. M. Organizatsionnye i pravovye voprosy prekrashcheniya sluzhby v organakh vnutrennikh del i sotsial'noy zashchity pensionerov: Avtoreferat dissertatsii na soiskanie uchenoy stepeni kandidata yuridicheskikh nauk. - M., 1999. - $22 \mathrm{~s}$.

7. Karavaev A.N. Pooshchrenie v sisteme pravookhranitel'noy sluzhby: Avtoreferat dissertatsii na soiskanie uchenoy stepeni kandidata yuridicheskikh nauk. — Saratov, 2005. - $24 \mathrm{~s}$.

8. Kontselidze R.U. Pravovaya i sotsial'naya zashchita sotrudnikov militsii: Avtoreferat dissertatsii na soiskanie uchenoy stepeni kandidata yuridicheskikh nauk. — M., 1993. — $20 \mathrm{~s}$.

9. Ovsyanko D.M. Gosudarstvennaya sluzhba Rossiyskoy Federatsii: Uchebnoe posobie. — M.: Yurist', 2008. — 447 s.

10. Pavlov O.F. Professional'naya pravovaya kul'tura v sfere pravookhranitel'noy sluzhby: Na primere sotrudnika militsii: Avtoreferat dissertatsii na soiskanie uchenoy stepeni kandidata yuridicheskikh nauk. — Novgorod, 2005. — $22 \mathrm{~s}$.

11. Pavlenko K.A. Sluzhebnaya distsiplina v sisteme pravookhranitel'noy sluzhby Rossiyskoy Federatsii: avtoreferat dissertatsii na soiskanie uchenoy stepeni kandidata yuridicheskikh nauk. — Voronezh, 2011. — $24 \mathrm{~s}$.

12. Pogrebezhskiy K.A. Pravovoe obespechenie gosudarstvennoy pravookhranitel'noy sluzhby i puti ego sovershenstvovaniya Avtoreferat dissertatsii na soiskanie uchenoy stepeni kandidata yuridicheskikh nauk. — M., 2010. - $26 \mathrm{~s}$.

13. Proletenkova S.E. Osobennosti realizatsii konstitutsionnykh prav svobody sovesti i svobody veroispovedaniya voennosluzhashchimi, sotrudnikami OVD i inykh pravookhranitel'nykh organov Avtoreferat dissertatsii na soiskanie uchenoy stepeni kandidata yuridicheskikh nauk. — SPb., 2005. — $21 \mathrm{~s}$.

14. Tsymbalov D.N. Obespechenie prav i zakonnykh interesov sotrudnikov organov vnutrennikh del: Konstitutsionnopravovye aspekty: Avtoreferat dissertatsii na soiskanie uchenoy stepeni kandidata yuridicheskikh nauk. SPb., 2005. - $23 \mathrm{~s}$. 